
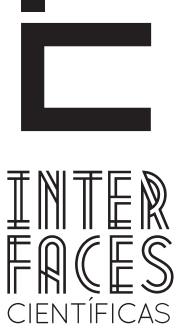

SAÚDE E AMBIENTE

\title{
ANÁLISE DAS SOLICITAÇÕES DE NOVA COLETA PARA UROCULTURA EM UM LABORATÓRIO NA CIDADE DE ARACAJU-SE
}

Larissa Rezende Mendonça ${ }^{1}$

Debora Machado Barreto ${ }^{3}$

Malone Santos Pinheiro
Plácia Barreto Prata ${ }^{2}$

Kariny Souza Pinheiro 4

\section{RESUMO}

As infecções do trato urinário (ITUs) ocorrem devido à invasão, multiplicação e colonização do trato urinário por bactérias e fungos. As ITUs são mais frequentes em crianças menores de 1 ano, em adultos do sexo feminino e idosos. O desenvolvimento de ITU está relacionado com estado imunológico, idade, uso abusivo de antimicrobianos e anormalidades morfofuncionais do trato urinário. Os microrganismos mais frequentemente envolvidos incluem bactérias da família Enterobacteriaceae. A urocultura é o melhor procedimento laboratorial para diagnóstico das ITUs. As situações mais incidentes quanto a não adequação das amostras para realização do exame estão associadas à coleta, transporte e armazenamento. 0 artigo teve como objetivo conhecer o índice de solicitações de nova coleta para urocultura em um laboratório clí- nico e avaliar os motivos dessas solicitações sugerindo medidas alternativas que minimizem seus inconvenientes. Foram obtidos dados existentes nos arquivos de solicitação de nova amostra do Laboratório Escola de Análises Clínicas da Universidade Tiradentes (UnitLab), situado em Aracaju/SE. No período de fevereiro de 2010 a dezembro de 2012, foram solicitadas 111 novas coletas para urocultura no UnitLab, sendo 31, em 2010, 38, em 2011 e 42, em 2012. Os motivos de solicitação de nova coleta foram amostra desprezada (3\%), armazenamento inadequado (6\%), confirmação de resultado (27\%), contaminação (59\%) e não definido (5\%). 0 resultado das novas coletas solicitadas para urocultura foi amostra negativa (51\%), pendente (32\%), amostra positiva (14\%) e contaminada (3\%). Para minimizar os inconvenientes sugere-se que haja 
uma maior comunicação entre o clínico e o paciente, na qual informações sobre os procedimentos de coleta, transporte e armazenamento sejam passadas, e que os laboratórios busquem melhorar a qualidade dos serviços prestados.

\section{ABSTRACT}

The urinary tract infections (UTIS) occur due to the invasion, multiplication and colonization of the urinary tract by bacteria and fungi. UTIs are more common in children under 1 year of age in women and older adults. The development of UTI is related to immune status, age, overuse of antibiotics and morphological and functional abnormalities of the urinary tract. The microorganisms most often involved include Enterobacteriaceae bacteria. A urine culture is the best laboratory procedure for the diagnosis of UTI. The most insidious situations as the unsuitability of the samples for the examination are associated with the collection, transportation and storage. The study aimed to know the rate of new collection requests for urine culture in a clinical laboratory and evaluate the reasons for such requests suggesting alternative measures to minimize their disadvantages. Existing data were obtained in the new sample request files School Laboratory of Clinical Analyses of the University Tira-

\section{PALAVRAS-CHAVE}

ITU. Urocultura. Não conformidade. Nova coleta. dentes (UnitLab), located in Aracaju / SE. From February 2010 to December 2012, 111 new samples were requested for urine culture in UnitLab, 31 in 2010, 38 in 2011 and 42 in 2012. The new collection request motifs were discarded sample (3\%), improper storage $(6 \%)$, confirming the results $(27 \%)$, infection (59\%) and not defined (5\%). The result of new samples requested for urine culture was negative sample (51\%), pending (32\%) Positive sample (14\%), contaminated (3\%). To minimize disruption suggests that there is greater communication between the clinician and the patient, in which information on collection procedures, transport and storage to be passed, and that laboratories seek to improve the quality of services provided.

\section{KEYWORDS}

UTI. Urine Culture. Non-Compliance. New Collection.

\section{RESUMEN}

Las infecciones del tracto urinario (ITU) se producen debido a la invasión, la multiplicación y la colonización del tracto urinario por bacterias y hongos. Las infecciones urinarias son más frecuentes en los niños menores de 1 año de edad, en mujeres adultas y ancianos. El desarrollo de ITU está asociada con el estado de inmunidad, edad, uso excesivo de antibióticos y anomalías morfofuncionales del tracto urinario. Los microorganismos implicados con más frecuencia son las bacterias de la familia Enterobacteriaceae. El cultivo de orina es el mejor procedimiento de laboratorio para el diagnóstico de las infecciones urinarias. Las situaciones más incidentes como la insuficiencia de las muestras para el examen están asociadas con la recolección, transporte y almacenamiento. El objeti- 
vo del estudio fue conocer la tasa de nuevas solicitudes de recogida del cultivo de orina en un laboratorio clínico y evaluar las razones de dichas solicitudes, y sugerir medidas alternativas para reducir al mínimo sus inconveniencias. Los datos existentes se obtuvieron en los archivos de solicitud de nuevas muestras del Laboratório Escola de Análises Clínicas da Universidade Tiradentes (UnitLab), que se encuentra en Aracaju/SE. Desde febrero de 2010 a diciembre de 2012, se solicitaron 111 nuevas muestras para cultivo de orina en UnitLab, siendo 31 en 2010, 38 en 2011 y 42 en 2012. Las razones de solicitud de nueva recolección fueron muestras despreciadas (el 3\%), almacenamiento inadecuado (el 6\%), la confirmación de

\section{INTRODUÇ̃̃̃O}

As infecções do trato urinário (ITUs) ocorrem devido à invasão, multiplicação e colonização do trato urinário por bactérias e, em menor proporção, fungos e vírus, que podem atingir tanto as vias urinárias superiores como inferiores. As ITUs situam-se entre as mais frequentes infecções bacterianas da população em geral, sendo prevalente em crianças menores de 1 ano, em adultos do sexo feminino, atingindo frequentemente mulheres com vida sexual ativa, gestantes e após menopausa, e nos idosos, acometendo ambos os sexos (LEITE ET AL., 2009; RODRIGUES ET AL., 2013).

O trato urinário é um ambiente estéril composto por rins, ureteres, bexiga e uretra. Essas estruturas são responsáveis pelo armazenamento e condução da urina produzida nos rins até o meio externo. A urina é constituída por uréia, ácido úrico, bicarbonato, potássio, sódio, entre outras substâncias químicas dissolvidas em água; é considerada um meio propício ao crescimento de microrganismos, os quais podem atingir outras regiões, passando a colonizar e invadir os tecidos, desenvolvendo processos infecciosos no trato urinário (COSTA, 2009; STRASINGER, 2009). resultado (el $27 \%$ ), infecciones (el $59 \%$ ) y no se definen (el 5\%). El resultado de las nuevas muestras de la cultura de la orina solicitadas fue negativo (el 51\%), a la espera (el 32\%), muestra positiva (el 14\%) y la contaminada (el 3\%). Para minimizar las inconveniencias se sugiere que exista una mayor comunicación entre el médico y el paciente, en la que informaciones sobre los procedimientos de recolección, traslado y almacenamiento sean dadas, y que los laboratorios busquen mejorar la calidad de los servicios prestados.

\section{PALABRAS CLAVE}

ITU. Cultivo de orina. No conformidad. Nueva recolección.

O desenvolvimento de ITU está relacionado com estado imunológico, idade, uso abusivo de antimicrobianos e anormalidades morfofuncionais do trato urinário. Fatores como a alteração na osmolalidade, na concentração de uréia, no pH urinário e altas concentrações de glicose na urina; presença de bexiga neurogênica; cálculos renais, vesicais ou prostáticos; utilização de cateteres e obstrução prostática benigna ou neoplásica favorecem a instalação do processo infeccioso (COSTA, 2009).

Os microrganismos mais frequentemente envolvidos nas ITUs incluem bactérias da família Enterobacteriaceae. 0 agente etiológico mais comum nos casos de infecção urinária é a Escherichia coli. Outros agentes como Klebsiella sp., Proteus sp., Enterobacter sp., Enterococcus faecalis, Pseudomonas aeruginosa, Staphylococcus saprophyticus também são capazes de desencadear o processo de infecção urinária (SILVA, 2008; RODRIGUES ET AL., 2013).

A maior incidência de infecções urinárias ocorre no sexo feminino. Devido a vulnerabilidade, as mulheres apresentam 50 vezes mais chances de adquirir ITU do que os homens e $30 \%$ delas possuem ITU sintomá- 
tica ao longo da vida. Como a via de contaminação do trato urinário é a ascendente, às mulheres apresentam uma maior predisposição devido a menor extensão anatômica da uretra e à maior proximidade entre a vagina e o ânus. A incidência de ITU nos homens aumenta após os 50 anos, onde a instrumentação das vias urinária e a ocorrência de doenças prostáticas são fatores que implicam no processo infeccioso. Os idosos e indivíduos hospitalizados correspondem ao grupo que apresenta maior susceptibilidade às infecções (RORIZ-FILHO ET AL., 2010).

A infecção urinária, quando compromete o trato urinário baixo, é diagnosticada como cistite. Quando acomete as vias superiores é denominada pielonefrite. A ITU pode ser sintomática ou não, aguda ou crônica, comunitária ou hospitalar. As cistites, apesar de apresentarem maior risco de falha terapêutica, não são consideradas infecções complicadas. Já as pielonefrites são geralmente consideradas infecções complicadas por desencadearem problemas de insuficiência renal (ARAÚJO \& QUEIROZ, 2012; RODRIGUES ET AL., 2013).

Quando não se sabe ao certo o que está ocasionando o processo infeccioso, adota-se a terapia empírica de forma imediata, baseando-se no perfil de susceptibilidade do microrganismo mais prevalente. Já para um tratamento mais específico é solicitada a urocultura, para que se determine o agente etiológico, e o antibiograma, para o direcionamento do tratamento. A terapia empírica inadequada pode acarretar no surgimento de ITU recorrente e de bactérias multirresistentes (COSTA, 2009).

A urocultura é o melhor procedimento laboratorial para diagnóstico das ITU, pois identifica o agente etiológico da infecção. Para que a amostra esteja dentro das conformidades é necessário que seja colhida a primeira urina da manhã ou que tenha um intervalo de duas a três horas entre as micções. 0 processo de coleta corresponde primeiramente a realização de uma assepsia rigorosa das genitais com água e sabão neutro, e posterior secagem com gaze estéril. Após desprezar o primeiro jato, coleta-se a urina num recipiente estéril. Em seguida, a amostra deve ser levada ao laboratório em temperatura ambiente no intervalo de uma hora após a coleta. 0 processo de análise deve ser feito dentro de duas horas. Caso não seja possível, a amostra deve ser armazenada em geladeira $\left(2^{\circ} \mathrm{C}\right.$ $-8^{\circ} \mathrm{C}$ ), não ultrapassando 24 horas (ANVISA, 2013).

A interpretação do quantitativo dos microrganismos na urina tem como referência três níveis: contagem acima de $100.000 \mathrm{UFC} / \mathrm{mL}$ é constatado infecção; entre 10.000 e 90.000 UFC/mL, suspeita-se de infecção; menor que $10.000 \mathrm{UFC} / \mathrm{mL}$, não apresenta significado clínico (GRIPPA; CALVI, 2009)

Contudo, inadequações pré-analíticas podem inferir negativamente na confiabilidade dos resultados. As situações mais incidentes quanto a não adequação das amostras para realização do exame estão associadas à coleta, transporte e armazenamento. A coleta inadequada, o transporte da amostra em temperatura acima dos padrões, manutenção da amostra por tempo prolongado em temperatura ambiente estão entre as principais não conformidades, pois resultam no crescimento de microrganismos (fungos e bactérias), levando a resultados falso-positivos (ANVISA, 2013; GRIPPA; CALVI, 2009).

A solicitação de nova coleta acaba ocasionando transtorno tanto para o laboratório como para o paciente, gera aumento de custos e de tempo dos profissionais envolvidos, incômodo e desconforto ao paciente, além da demora em se chegar ao diagnóstico o que pode ocasionar complicações da infecção no paciente. Diante do exposto, o presente artigo teve como objetivo conhecer o índice de solicitações de nova coleta para urocultura em um laboratório clínico e avaliar os motivos dessas solicitações, sugerindo medidas alternativas que minimizem seus inconvenientes.

\section{MATERIAL E MÉTODOS}

Trata-se de um estudo retrospectivo, descritivo e transversal, onde foram utilizados dados existentes nos arquivos de solicitação de nova amostra do Laboratório Escola de Análises Clínicas da Universidade Tiradentes (UnitLab), situado em Aracaju/Sergipe, entre fevereiro de 2010 a dezembro de 2012. 
Foi realizado um estudo exploratório dos dados obtidos a partir dos arquivos supracitados, sendo em seguida, executado a análise descritiva com tabulação dos resultados em planilha do programa Microsoft Word Excel ${ }^{\circledR} 2007$.

0 presente trabalho foi dispensado de submissão ao Comitê de Ética e Pesquisa por não tratar-se de pesquisa com seres humanos ou animais.

\section{RESULTADOS E DISCUSSÃO}

No período de fevereiro de 2010 a dezembro de 2012, foram solicitadas no Laboratório Central de Biomedicina (UnitLab), 31 novas coletas para urocultura no ano de 2010, em 2011 foram 38 e 42 coletas em 2012, demonstrando uma crescente em seus valores absolutos nos anos pesquisados.

Os motivos de solicitação de nova coleta foram: amostra desprezada (3\%), motivo não definido (5\%), armazenamento inadequado (6\%), confirmação de resultado (27\%) e amostra contaminada (59\%). As amostras desprezadas condizem àquelas que tinham solicitação para urocultura, mas devido a um erro de cadastro o exame não foi realizado. As amostras com armazenamento inadequado foram aquelas que ultrapassaram o prazo recomendado de duas horas entre a coleta e a refrigeração e/ou processamento. Já as novas coletas solicitadas para confirmação de resultado foram aquelas que obtiveram crescimento de microrganismos sem significado clínico (não uropatógeno) ou com contagens insignificantes.

Foram classificadas como amostras contaminadas as que apresentaram crescimento superior a três microrganismos de espécies distintas (ANVISA, 2013) e não definido representa as amostras que não foi atribuído um motivo para nova coleta.

No presente estudo observou-se que $65 \%$ das solicitações de nova amostra foram devido ao condicionamento ou coleta inadequada do espécime clinico e referem-se, portanto, a fase pré-analítica. A fase pré-analítica compreende a preparação do paciente, a anamnese, a coleta e o armazenamento de amostras, sen- do a etapa que antecede o processamento laboratorial (COSTA e MORELI, 2012). Segundo Goswani e outros autores (2010) mais de $70 \%$ das não-conformidades ocorrem nesta fase. 0 estudo realizado por Wislocki (2011), também, evidencia que a fase pré-analítica é responsável por mais da metade das não conformidades, o que acarreta na solicitação de nova coleta.

A atenção redobrada do laboratório clínico para a fase pré-analítica deve trazer muitos benefícios na redução dos erros de diagnóstico. Na última década esses erros têm sido a causa mais comum de reivindicações judiciais nos Estados Unidos (PHILLIPS ETAL., 2004; ELSTON, 2008). Esse fato exige que os laboratórios clínicos assumam a responsabilidade por todo o ciclo dos testes laboratoriais e busquem ferramentas que auxiliem na redução de erros laboratoriais que levam à erros diagnósticos (PLEBANI, 2006).

Melhorias referentes à fase pré-analítica podem ser obtidas por meio do treinamento constante dos profissionais envolvidos no preparo do paciente para essa fase, bem como, na implantação de um programa de gestão da qualidade. Esse programa torna-se o caminho mais eficaz para a melhoria dos processos dentro do laboratório por meio de uma gestão de riscos e na busca da melhoria continua nos processos laboratoriais (GUIMARÃES, ET AL., 2011).

Observa-se ainda que inadequações quanto à preservação e transporte da amostra ocorreram possivelmente devido a falta de informação do paciente no que concerne a sua estabilidade. De acordo com ANVISA (2013), a coleta e o transporte inadequados relacionam-se com a perda da viabilidade da amostra que posteriormente ocasionam erros na fase analítica propriamente dita, a exemplo de identificações e perfil de susceptibilidade aos antimicrobianos equivocados devido estar relacionado com o desenvolvimento de microbiota contaminante.

Como mencionado anteriormente, a falta de informação sobre a realização de exames acarreta aumento de não conformidades das amostras. Segundo Costa e Moreli (2012), 64,3\% dos pacientes não foram informados adequadamente sobre os procedimentos para obtenção das amostras e as variáveis 
dessa conduta. Acredita-se que o elevado percentual de amostras contaminadas é devido a não realização de assepsia correta, não utilização de coletor estéril, atraso na entrega do material ou armazenamento inadequado. Esse tipo de informação pode ser crucial para o cumprimento de uma boa fase pré-analítica que será fundamental para a obtenção de resultados verídicos. Essas informações devem ser fornecidas aos pacientes durante a consulta médica e também pelo laboratório clínico.

0 resultado das novas coletas, solicitadas para urocultura, apresentou um percentual de $51 \%$ de amostras negativas, fornecendo assim um resultado final aceitável e confiável. Porém, o percentual de pacientes que não retornaram ao laboratório para realização do exame foi bastante significativo, representando 32\% (Figura 1).
O elevado número de amostras pendentes pode ser devido à insatisfação do paciente em retornar ao laboratório, sendo que muitos deles não residiam no mesmo município do laboratório clínico, devido também ao desconforto de ter que realizar novamente todo processo de coleta, armazenamento e transporte da amostra e, muitas vezes, por não apresentarem mais os sintomas/infecção devido ao uso de terapia empírica.

Essas informações coadunam com Guimarães e outros autores (2011) que afirmam ser a solicitação não criteriosa de nova coleta importante geradora de insatisfação, ansiedade, transtornos e insegurança ao médico e ao paciente. Já para o laboratório clínico, geram custos desnecessários, demora na liberação do laudo, trabalho dobrado e ainda o mais importante, a perda da credibilidade, confiança e segurança.

Figura 1 - Análise percentual dos resultados das uroculturas após obtenção de nova amostra

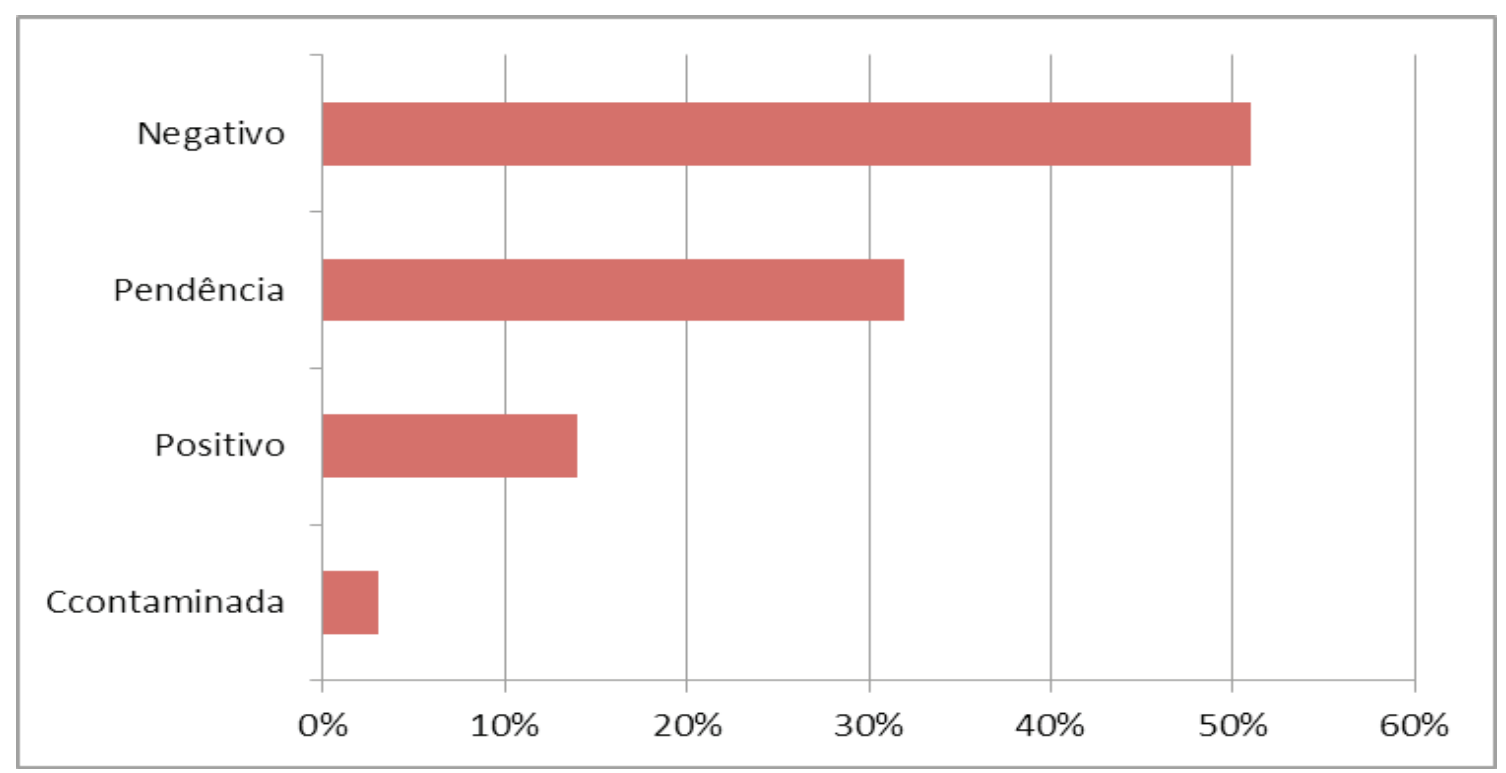

Fonte: Dados da pesquisa, 2014. 
Ao realizar um estudo comparativo entre os resultados da primeira amostra e da nova coleta, observou-se que entre as amostra desprezadas, após a nova coleta, apenas uma obteve resultado positivo; uma permaneceu em pendência e uma apresentou-se negativa. Das amostras com armazenamento inadequado, quatro permaneceram pendentes e três, foram negativas. Das amostras que precisavam confirmar resultado, uma apresentou contaminação; quatro permaneceram positivas; nove pendentes e 16 foram negativas. Entre as amostras contaminadas, duas permaneceram contaminadas; 10 apresentaram-se positivas; 21 ficaram pendentes e 32, foram negativas. Das amostras que não tinham o motivo de nova solicitação, uma foi positiva; uma permaneceu pendente e, quatro foram negativas (Tabela 1).

0 número elevado de amostras que inicialmente apresentam-se contaminadas e que após a solicita- ção de nova coleta obtiveram resultados negativos, evidencia a ocorrência de erro no procedimento de coleta, transporte ou armazenamento da amostra, o que sugere uma eventual falta de comunicação entre o clínico e o paciente, indicando assim, a importância da instrução dos pacientes sobre os procedimentos adequados na obtenção de amostras para realização de exames.

De acordo com Rodrigues e outros autores (2014) os critérios de aceitação e rejeição de amostras, assim como a realização de análises em amostras com restrições devem estar bem definidos e documentados no laboratório clínico. Esse nível organizacional do laboratório clínico será fator preponderante para o fornecimento de resultados condizentes com a condição clínica do paciente, evitará a solicitação de novas amostras desnecessariamente, também trará maior agilidade ao processo diagnóstico.

Tabela 1 - Comparação entre os resultados da primeira amostra e a nova coleta

\begin{tabular}{llllll}
\hline & $\begin{array}{c}\text { Amostra } \\
\text { Desprezada }\end{array}$ & $\begin{array}{c}\text { Armazenamento } \\
\text { Inadequado }\end{array}$ & $\begin{array}{c}\text { Confirmação de } \\
\text { Resultado }\end{array}$ & Contaminação & Não Definido \\
\hline Contaminação & 0 & 0 & 1 & 2 & 0 \\
Positivo & 1 & 0 & 4 & 10 & 1 \\
Pendência & 1 & 4 & 9 & 21 & 1 \\
Negativo & 1 & 3 & 16 & 32 & 4 \\
\hline
\end{tabular}

Fonte: Dados da pesquisa, 2014. 


\section{CONCLUSÃO}

Diante do exposto concluiu-se que a análise dos resultados das recoletas mostrou que a maioria das amostras estava em condições adequadas para análise, evidenciando que os procedimentos de coleta, transporte e armazenamento foram feitos corretamente. Pode-se observar ainda que diferentes fatores estão envolvidos nos erros de laboratório clínico, principalmente na fase pré-analítica e que o constante treinamento dos profissionais envolvidos nessa fase pode ajudar na redução do número de não conformidades.

A intensificação da comunicação entre o clínico e o paciente surge como uma importante alternativa, onde informações sobre os procedimentos de coleta sejam fornecidas de forma clara ao paciente gerariam diminuição nas inadequações referentes a transporte e armazenamento da amostra.

Faz-se necessário, ainda, que os laboratórios busquem melhorar a qualidade dos serviços prestados por meio da contratação de profissionais capacitados, o que fornece maior confiabilidade sobre os resultados, e que esses priorizem uma ótima relação com o paciente e atenção no cadastro dos exames.

\section{REFERÊNCIAS}

ANVISA. Procedimentos laboratoriais: da requisição do exame procedimentos laboratoriais: da requisição do exame à análise microbiológica e laudo final. Módulo IV, 2013.

ARAUJO, K. L.; QUEIROZ, A. C. Análise do perfil dos agentes causadores de infecção do trato urinário e dos pacientes portadores, atendidos no Hospital e Maternidade Metropolitano-SP. J Health Sci Inst., 30(1):7-12, 2012.

COSTA, F. C. Prevalência e perfil de susceptibilidade a antimicrobianos de microrganismos isolados em urocultura no período de janeiro a dezembro de
2007, em Hospital Municipal de lbirité/MG. Belo Horizonte, 2009.

COSTA V. G.; MORELI, M. L. Principais parâmetros biológicos avaliados em erros na fase pré-analítica de laboratórios clínicos: revisão sistemática. J Bras Patol Med Lab., v.48, n.3, 2012. p.163-168.

ELSTON DM. Opportunities to improve quality in laboratory medicine. Clin Lab Med. 28(2):173-7, 2008.

GOSWAMI, B.; SINGH, B.; CHAWLA, R.; MALLIKA, V. Evaluation of errors in a clinical laboratory: a oneyear experience. Clinical Chemistry and Laboratory Medicine, 48, 2010. p.63-66.

GUIMARÃES, A. C.; WOLFART, M; BRISOLARA, M. L. L.; DANI, C. O laboratório clínico e os erros préanalíticos. Rev HCPA. 31(1):66-72, 2011.

GRIPPA, A. A.; CALVI, P. E. Avaliação do impacto da conservação e transporte de amostra de urina para cultura. Vitória/ES: Faculdade Brasileira - UNIVIX, 2009.

LEITE, A. B. et al. Frequência de bactérias gram-negativas em uroculturas de pacientes ambulatoriais, do sistema único de saúde (SUS) de Maceió (AL), e sua sensibilidade a antibióticos. RBAC, 41(1):15-20, 2009.

PHILLIPS R. L. JR, et al. Learning from malpractice claims about negligent, adverse events in primary care in the United States. Qual Saf Health Care, 13(2):121-126, 2004.

PLEBANI M. Errors in clinical laboratories or errors in laboratory medicine? Clin Chem Lab Med., 44:50-59, 2006.

RODRIGUES, C. E. F. B.et al. Perfil Epidemiológico das Infecções Urinárias Diagnosticadas em Pacientes Atendidos no Laboratório Escola da Universidade Potiguar. NewsLab., 119.ed. Natal, RN, 2013. 
RODRIGUES M, XAVIES I. D. A., CARDOSO A. M. Amostras urinárias: avaliação da fase pré-analítica em um laboratório clínico de Goiânia-Go, Unidade Matriz e Posto De Coleta. Estudos, v.41, n.3, Goiânia, jul./set. 2014. p.615-625.

RORIZ-FILHO, J. S. et al. Infecção do trato urinário. Medicina (Ribeirão Preto) 43(2):118-25. Disponível em: <http://www.fmrp.usp.br/revista>. Acessado em: 10 de Fev. 2015.
SILVA, C.H.P.M. Protocolo de Microbiologia Clínica: Urocultura - Parte 3. NewsLab., 88. ed., 2008.

STRASINGER, S K; DI LORENZO, M S. Urinálise e fluidos corporais, 5.ed. São Paulo: Livraria Médica Paulista, 2009.

WISLOCKI, V. D. Levantamento das não conformidades laboratoriais e suas consequências clínicas em uma unidade hematológica hospitalar. Rio Grande do Sul: UFRS, Faculdade de Medicina, 2011.
1. Biomédica - Universidade Tiradentes - UNIT/SE.

2. Biomédica, Doutora em Biotecnologia, Professora da Universidade Tiradentes - UNIT/SE.

3. Biomédica, Mestre em Biologia Parasitária. Doutoranda em Biotecnologia. E-mail: barreto@hotmail.com

4. Biomédica, Mestre em Saúde e Ambiente pela Universidade Tiradentes UNIT/SE.

5. Doutor em Biotecnologia, Professor da Universidade Tiradentes - UNIT/SE. E-mail: malonepinheiro@hotmail.com 